\title{
II:
}

\section{ANÁLISE DE DESEMPENHO DO TRANSFORMADOR DE POTÊNCIA ISOLADO A ÓLEO VEGETAL EM RELAÇÃO AO TRANSFORMADOR DE POTÊNCIA ISOLADO A ÓLEO MINERAL}

\author{
PERFORMANCE ANALYSIS OF VEGETABLE OIL ISOLATED POWER \\ TRANSFORMER IN RELATION TO MINERAL OIL INSULATED POWER \\ TRANSFORMER
}

${ }^{1}$ Larissa Santos Almeida

${ }^{2 *}$ Pablo Rodrigues Muniz

${ }^{1}$ Instituto Federal do Espírito Santo - Campus Vitória. E-mail: larissaac2@gmail.com
${ }^{2}$ Instituto Federal do Espírito Santo - Campus Vitória. E-mail: pablorm@ifes.edu.br
*Autor de correspondência

Artigo submetido em 30/04/2020, aceito em 04/06/2020 e publicado em 28/08/2020.

\begin{abstract}
Resumo: A utilização dos transformadores de potência é imprescindível para a continuidade de operação do sistema elétrico. Um dos componentes importantes do transformador é o óleo isolante, responsável por seu isolamento elétrico interno e sua refrigeração. Com a crescente preocupação ambiental, viu-se a necessidade de buscar novas alternativas para o sistema de isolamento dos transformadores, uma vez que o óleo mineral isolante é proveniente do petróleo, considerado tóxico, nocivo ao ambiente e de baixa biodegradabilidade. Pesquisas atuais mostraram que o óleo vegetal isolante é uma alternativa a ser considerada por empresas do setor elétrico, por ser um fluido biodegradável, com ponto de fulgor e combustão elevados, sendo caracterizado como um fluido com maior segurança. Este trabalho analisa as vantagens técnicas e operacionais da utilização do óleo vegetal isolante comparado com o óleo mineral isolante. São verificadas suas características físicoquímicas, implicações ambientais em caso de derramamento, bem como implicações de segurança quanto ao ambiente de instalação. Conclui-se que o óleo vegetal apresenta vantagens na maioria dos aspectos operacionais e ambientais e também nos requisitos de instalação para segurança e confiabilidade operacionais.
\end{abstract}

Palavras-chave: transformador de potência; distribuição de energia; óleo isolante; óleos vegetais; avaliação de desempenho.

Abstract: Power transformers are essential for operational continuity of the electrical system. Insulating oil is one of the important components of the transformer, responsible for its internal electrical insulation and cooling. With the growing environmental concern, it was needed to seek new alternatives for the isolation system of transformers, since the insulating mineral oil comes from petroleum, considered toxic, harmful to the environment and of low biodegradability. Current research has shown that insulating vegetable oil is an alternative to be considered by companies in the electrical sector, as it is a biodegradable fluid, with a high flash and high combustion temperatures, being characterized as a high safe fluid. This paper analyzes the technical and operational advantages of using insulating vegetable oil compared to insulating mineral oil. Its physical-chemical characteristics, environmental implications in case of spillage, as well as safety implications regarding the installation 
environment are checked. It is concluded that vegetable oil has advantages in most operational aspects, in environmental aspects and also in the installation requirements for operational safety and reliability.

Keywords: power transformer; power distribution; oil insulation; vegetable oils; performance analysis.

\section{INTRODUÇÃO}

No Sistema Elétrico de Potência (SEP), um equipamento que possui grande importância é o transformador, pois é responsável pela elevação ou diminuição da tensão elétrica das linhas de transmissão e redes de distribuição (NOGUEIRA; ALVES, 2009; OLIVEIRA, 2009). A parada operacional de um transformador pode acarretar multas perante órgãos reguladores (MOURA; ANDRADE, 2017). Por ser um equipamento robusto que suporta tensões elevadas e possuir em seu sistema de refrigeração fluido isolante, se ocorrer alguma falha durante a operação, o sistema pode vir a ter grandes problemas, como até mesmo a ocorrência de uma explosão (GOUVEIA, 2008).

O principal elemento de um transformador é sua parte ativa, composta de enrolamentos e núcleo. A fim de evitar a passagem de corrente entre as espiras de uma mesma bobina, são utilizados papéis isolantes ou outro isolante sólido. Durante a operação do transformador, a corrente que circula pelas espiras faz com que haja aquecimento, devido à sua resistência. $\mathrm{O}$ calor gerado pode causar degradação térmica do material isolante contido entre as espiras. Desse modo, é necessária a utilização de fluidos isolantes para a refrigeração das espiras de material condutor (DATALINK, 2016; SIMONE, 2017). Na Figura 1 pode-se observar a circulação do óleo isolante dentro de um transformador de potência durante a sua operação. O óleo isolante circula geralmente por convecção entre a parte ativa, contida no tanque principal, ganhando calor, e o radiador externo ao tanque, irradiando esse calor para o ambiente.
Quando analisadas as propriedades e características dos fluidos isolantes, pode-se observar que quanto melhor forem essas características, mais econômico o projeto se torna, pela redução de isolante sólido, das distâncias entre as espiras, entre as bobinas e núcleo e entre estes as partes aterradas (DATALINK, 2016).

Figura 1: Circulação de óleo isolante pela parte ativa e pelo radiador do transformador

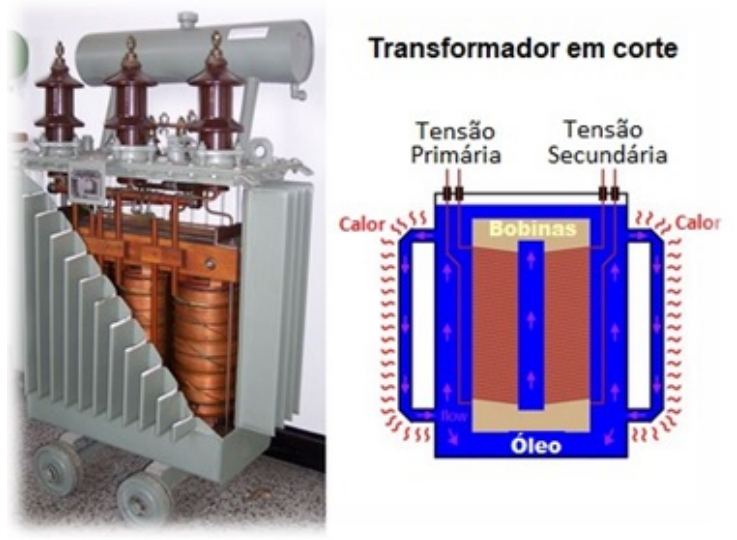

Fonte: (SEG MAQS, 2020)

A crescente busca por alternativas que diminuam o impacto no meio ambiente também se consolidou no setor elétrico (FEIL et al., 2017). Existem muitos estudos sendo feitos para a utilização do óleo vegetal isolante (OVI) em substituição ao óleo mineral isolante (OMI), a fim de se obter um fluido com a mesma finalidade do óleo mineral em transformadores de potência e que sejam biodegradáveis, menos inflamáveis e não tóxicos à saúde (WILHELM; TULIO; UHREN, 2009). Além da preocupação em relação ao meio ambiente, distribuidoras de energia elétrica também buscam por características que influenciam na eficiência de operação, segurança contra explosões e incêndios, e extensão da expectativa de vida util. 
O transformador de potência isolado a OMI surgiu em 1882 com a ideia de que uso do óleo mineral contribuiria na redução das dimensões do equipamento e na melhoria de sua eficiência, comparado com os primeiros transformadores a seco. $\mathrm{Na}$ atualidade, o OMI é o fluido dielétrico mundialmente mais utilizado no setor elétrico. O baixo custo do OMI, sua alta disponibilidade e excelentes propriedades dielétricas fizeram com que se consolidasse no mercado como fluido isolante para equipamentos elétricos (SIMONE, 2017). O transformador de potência isolado a OVI surgiu naquela mesma época, final do século XIX. Porém, nos primeiros experimentos, os óleos vegetais se mostraram menos atrativos do que os óleos minerais devido à sua estabilidade de oxidação, permissividade, ponto de fluidez e viscosidade distintas. No entanto, devido à crise do mercado de petróleo nos anos 1970, surgiu um novo estímulo: buscar fontes biodegradáveis alternativas para aplicação em transformadores. Por volta do ano de 1999 foram desenvolvidos OVIs apropriados para a aplicação em transformadores de potência (FEIL et al., 2017; GUIMARÃES et al., 2019; STOCCO, 2010; WILHELM; TULIO; UHREN, 2009). A partir disso, diversas distribuidoras de energia elétrica brasileiras têm substituído transformadores a OMI por transformadores a OVI não só em suas redes de distribuição, mas também em subestações. São exemplos: Companhia Paulista de Força e Luz (CPFL), Companhia Energética de Minas Gerais (Cemig), Centrais Elétricas de Santa Catarina (Celesc), Energias de Portugal (EDP), Companhia Estadual de Energia Elétrica (CEEE), Companhia Paranaense de Energia ( Copel), Light, Ente nazionale per l'energia elettrica (Enel), e Empresa Luz e Força Santa Maria (ELFSM) (CARGILL， 2018a, 2020; MARTINS, 2017).

A obtenção do óleo mineral é realizada a partir do refino de uma parcela de hidrocarbonetos que são obtidos por intermédio da destilação do petróleo, onde suas características podem variar dependendo da tecnologia empregada durante $\mathrm{o}$ procedimento (ZIRBES; ROLIM; ZÜRN, 2005). A mistura dos compostos é, em sua maioria, de moléculas constituídas de carbono e hidrogênio e em pequenas porções de moléculas de nitrogênio, enxofre e oxigênio (STOCCO, 2010). Nesse contexto, o derramamento ou vazamento desse óleo pode ser muito prejudicial para o meio ambiente, visto que contamina o solo e o sistema hídrico, sendo considerado um óleo tóxico (SIMONE, 2017).

Com o vazamento de óleo mineral isolante, os componentes de hidrocarbonetos podem migrar com infiltração de água de chuva até o lençol freático, contaminando a água, tornando-a imprópria para consumo e aumentando custos para o tratamento (FRIEDENBERG; SANTANA, 2014).

A composição do óleo vegetal é feita a partir de oleaginosas como milho, girassol, soja, etc. Essas matérias primas utilizadas na produção do OVI são fontes renováveis e totalmente naturais, o que as torna uma excelente opção para empresas que se preocupam com a preservação do meio ambiente (WILHELM; TULIO; UHREN, 2009). Por ser um óleo obtido por meio de sementes oleaginosas, ele é considerado altamente biodegradável. Os OVIs tendem a formar cadeias mais longas de ácidos graxos devido ao seu alto índice de neutralização, fazendo com que esse óleo seja menos agressivo ao meio ambiente (STOCCO, 2010).

Dentro dessa contextualização, este trabalho aborda o tema fazendo uma comparação técnica da utilização do óleo vegetal em relação ao óleo mineral. Dessa forma, o principal objetivo é analisar as vantagens e desvantagens da utilização do transformador de distribuição isolado a óleo vegetal em relação ao transformador de distribuição isolado a óleo mineral, no que tange a propriedades físico-químicas e 
consequente manutenibilidade do transformador; ao impacto na vida útil do transformador; aos impactos ambientais durante a operação do transformador; e à segurança operacional.

\section{COMPARAÇÕES \\ ENTRE \\ TRANSFORMADORES \\ DE \\ POTENCIA ISOLADOS A ÓLEO MINERAL E ÓLEO VEGETAL}

A análise das propriedades físicoquímicas do OMI e do OVI foi feita por meio de parâmetros estabelecidos em normas da Associação Brasileira de Normas Técnicas (ABNT). A Tabela 1 apresenta os diferentes parâmetros determinados pelas normas técnicas para análise físico-química do OVI e do OMI.

Tabela 1: Ensaios de características físico-

\begin{tabular}{|c|c|c|c|c|}
\hline \multicolumn{2}{|l|}{ Característica } & Unidade & OVI & OMI \\
\hline \multicolumn{2}{|c|}{ Ponto de Combustão (mínimo) } & ${ }^{\circ} \mathrm{C}$ & 300 & 160 \\
\hline \multicolumn{2}{|c|}{ Ponto de Fulgor (mínimo) } & ${ }^{\circ} \mathrm{C}$ & 275 & 140 \\
\hline \multicolumn{2}{|c|}{ Densidade a $20 / 4{ }^{\circ} \mathrm{C}^{*}$ (máximo) } & --- & 0,96 & 0,90 \\
\hline \multirow{3}{*}{ Viscosidade (máxima) } & a $20^{\circ} \mathrm{C}$ & & 150 & 25 \\
\hline & a $40{ }^{\circ} \mathrm{C}$ & $\mathrm{cSt}$ & 50 & 12 \\
\hline & a $100{ }^{\circ} \mathrm{C}$ & & 15 & 3 \\
\hline \multicolumn{2}{|l|}{ Teor de Água (máximo) } & $\mathrm{mg} / \mathrm{kg}$ & 200 & 35 \\
\hline \multicolumn{2}{|c|}{ Índice de neutralização (máximo) } & $\mathrm{mg} \mathrm{KOH} / \mathrm{g}$ & 0,06 & 0,03 \\
\hline \multirow{2}{*}{$\begin{array}{l}\text { Rigidez } \\
\text { dielétrica } \\
\text { (mínima) }\end{array}$} & \multirow{2}{*}{$\begin{array}{l}\text { Eletrodo de } \\
\text { disco } \\
\text { Eletrodo de } \\
\text { calota }\end{array}$} & & 30 & 30 \\
\hline & & $\mathrm{kV} / 2,5 \mathrm{~mm}$ & 42 & 42 \\
\hline
\end{tabular}

* Densidade do óleo isolante a $20^{\circ} \mathrm{C}$ em relação à densidade da água a $4{ }^{\circ} \mathrm{C}$.

Fonte: Normas Técnicas ABNT NBR 11341, 7148, $10441,15422,14248$ e 6869

\subsection{ANÁLISE DE VIDA ÚTIL DOS} TRANSFORMADORES ISOLADOS A OVI E OMI

A vida útil de transformadores de potência normalmente é estimada por seu fabricante. Uma vez que a taxa de degradação dos materiais celulósicos, ou seja, do papel isolante é significantemente mais baixa quando imersos em óleo vegetal isolante, a vida útil do papel isolante é estendida, e consequentemente a do transformador. Conforme apresentado na Tabela 1, observa-se que o óleo vegetal isolante possui maior tolerância, aceitação, a água em si dissolvida, comparando-o com o óleo mineral. Dessa forma, a água possui facilidade de migração da isolação sólida para o líquido isolante vegetal, o que implica na diminuição da umidade na isolação sólida, fazendo com que a sua vida útil aumente. A Tabela 2 evidencia estudos feitos pelo fabricante $\mathrm{ABB}$ referente a expectativa de vida útil do transformador de potência isolado a óleo mineral versus óleo vegetal, considerando diferentes temperaturas de operação. Observa-se que a expectativa de vida útil do OVI é de aproximadamente duas vezes maior do que a do OMI.

Tabela 2: Expectativa de vida útil do transformador de potência isolado a óleo mineral versus óleo vegetal - ambos casos com papel isolante classe $55^{\circ} \mathrm{C}$

\begin{tabular}{ccc}
\hline \multirow{2}{*}{$\begin{array}{c}\text { Temperatura do ponto } \\
\text { mais quente do } \\
\text { Transformador } /{ }^{\circ} \mathbf{C}\end{array}$} & \multicolumn{2}{c}{$\begin{array}{c}\text { Expectativa de vida do } \\
\text { transformador } / \mathbf{h}\end{array}$} \\
\cline { 2 - 3 } & $\begin{array}{c}\text { Óleo Mineral } \\
\text { Isolante }\end{array}$ & $\begin{array}{c}\text { Óleo Vegetal } \\
\text { Isolante }\end{array}$ \\
\hline 85 & 220.000 & 440.838 \\
95 & 65.000 & 130.335 \\
100 & 36.232 & 72.626 \\
105 & 20.500 & 41.100 \\
110 & 11.800 & 23.607 \\
120 & 4.050 & 8.125 \\
\hline
\end{tabular}

Fonte: (MENDES, 2008)

2.2 IMPACTOS AMBIENTAIS CAUSADOS PELO DERRAMAMENTO DE ÓLEO ISOLANTE

O OMI pode sofrer oxidação em contato com umidade, oxigênio e o cobre dos enrolamentos durante um longo período de utilização. Essa oxidação faz com que sejam originados hidroperóxidos e peróxidos que se depositam no fundo dos tanques e, por sua vez, dão origem a outros produtos, tais como álcoois, aldeídos, cetonas, ésteres, ácidos, sabões metálicos e água. Esse óleo se mostrou perigoso ao meio ambiente, e difícil de ser feito o seu descarte pois ele é altamente poluente, e pode degradar o meio ambiente com muita intensidade. Para se ter a exata noção dessa poluição, um litro de óleo isolante mineral 
pode contaminar um milhão de litros de água (DA SILVA, 2009).

Como exemplo, cita-se a catástrofe ocorrida no ano de 2012 em uma subestação da Celesc, no estado de Santa Catarina, Brasil. Os detalhes do incidente estão disponíveis para a comunidade. Vazaram cerca de doze mil litros de óleo mineral isolante, contaminando e comprometendo o equilíbrio ambiental do local atingido. Inicialmente, foram contaminados o solo e o lençol freático, ocasionando a morte da vegetação próxima à subestação e ameaçando toda fauna que possuía aquele ambiente como habitat. Além disso, o óleo escorreu até a margem de um estreito curso de água onde se dissipou ainda mais, tornando o desastre muito maior. Os impactos também causaram prejuízos à economia das comunidades que ali habitavam. O local era explorado por comerciantes que tiravam o sustento dos produtos de origem marinha (GARCIA, 2014).

A fim de se minimizar os impactos ambientais causados por derramamento de óleos minerais isolantes, agências reguladoras governamentais já estão aplicando penalidades mais severas para tais acidentes (BECHARA, 2010). A quantificação econômica dessas multas pode ser feita por meio da abordagem de riscos estatísticos da ocorrência de derramamento do hidrocarboneto, considerando sua frequência e valores monetários associados (DA SILVA; MATA-LIMA, 2019).

O OVI, por ser um óleo que possui cadeias longas e ácidos graxos, é bem menos nocivo ao meio ambiente. As características desejadas a um fluido isolante para não agressão à saúde são a não toxicidade, a biodegradabilidade, produção aceitável com baixo risco térmico, ser reciclável, ter facilidade no descarte, e a degradação de subprodutos inertes. O fluido não derivado de petróleo é uma proposta que atende a todos esses critérios, com a vantagem adicional de ser renovável, ao contrário dos óleos minerais. Por ser um óleo obtido a partir de oleaginosas, o OVI é um fluido biodegradável, onde sua deterioração se dá até no máximo 28 dias (WILHELM; TULIO; UHREN, 2009).

O derramamento do OVI no solo não causa impactos que prejudicam o meio ambiente, e o óleo pode ser limpo utilizando flanelas absorventes. A inerente viscosidade do fluido $\mathrm{e}$ tendência à polimerização de suas camadas finas em um ambiente externo ajudam a prevenir a infiltração do fluido da superfície para o subsolo. Já o derramamento do OVI na água pode ser uma preocupação do ponto de vista ambiental, pois ele se espalha facilmente, prejudicando animais pertencentes ao corpo d'água. Esse óleo não é considerado um contaminante grave nem tóxico, porém é um contaminante de altas proporções em volume.

O vazamento do óleo vegetal isolante pode ser contido pelo uso de flutuadores ou diques, ou pela aplicação de dispersantes químicos tensoativos, conhecidos também como detergentes, que são projetados para remover o óleo da superfície da água e dentro da coluna de água (CARGILL, 2007).

A Tabela 3 apresenta as quantidades de gases de efeito estufa gerados desde a matéria prima até o final de vida para óleo mineral e óleo vegetal. O impacto ambiental total do óleo vegetal isolante (mais especificamente o fluido FR3) é cerca de $1 / 4$ do impacto reportado para óleo mineral (CARGILL, 2007).

\subsection{SEGURANÇA OPERACIONAL DOS TRANSFORMADORES ISOLADOS A OVI E OMI}

Devido ao alto ponto de combustão do OVI, em torno de $300{ }^{\circ} \mathrm{C}$ contra $160{ }^{\circ} \mathrm{C}$ do OMI, o OVI se torna um fluido considerado resistente ao fogo. Ensaios realizados pela Cargill mostraram que a probabilidade de um incêndio evoluir a 
partir do OVI é tão baixa que a taxa de liberação de calor não precisou ser determinada ou considerada para aprovação de uso por companhias seguradoras. Com base nesses experimentos, o OVI desenvolvido pela Cargill foi reconhecido como meio de segurança com características equivalentes às distâncias de separação, paredes cortafogo e sistemas de extinção de incêndio aplicadas a diversas instalações (CARGILL, 2007). A Tabela 4 ilustra a taxa de perigo ao fogo de diferentes tipos de óleo isolante (UNDERWRITERS LABORATORIES, 2017).

Tabela 3: Gases de Efeito Estufa atribuídos ao fluido do transformador em seu ciclo de vida completo

\begin{tabular}{|c|c|c|}
\hline \multirow{2}{*}{$\begin{array}{lcr}\text { Etapa } & \text { do } & \text { ciclo de } \\
\text { vida } & \text { do } & \text { fluido } \\
\text { isolante } & & \end{array}$} & \multicolumn{2}{|c|}{$\begin{array}{l}\text { Toneladas de gases de efeito estufa } \\
\text { por } 1.000 \text { galões de óleo isolante }\end{array}$} \\
\hline & OMI & OVI - FR3 \\
\hline Matéria-prima & 2,306 & $-0,839$ \\
\hline Produção & 1,198 & 0,352 \\
\hline Transporte & 0,269 & 0,157 \\
\hline Utilização & 0,339 & 0,338 \\
\hline Final de vida & 0,068 & 0,068 \\
\hline Total & 4,180 & 0,075 \\
\hline
\end{tabular}

Fonte: (CARGILL, 2007)

Tabela 4: Taxa de perigo ao fogo de diferentes fluidos conforme norma UL 340

\begin{tabular}{cc}
\hline Fluido & Taxa de perigo ao fogo $/ \%$ \\
\hline Água & 0 \\
Ascarel & 2 a 3 \\
OVI (FR3) & 4 a 5 \\
OMI & 10 a 20 \\
Querosene & 30 a 40 \\
Gasolina & 90 \\
\hline
\end{tabular}

Fonte: (CARGILL, 2007; UNDERWRITERS LABORATORIES, 2017)

Nesse contexto de perigo ao fogo, a Erro! Autoreferência de indicador não válida. apresenta as distâncias mínimas exigidas para separação entre transformadores de potência e outros equipamentos quando não há parede de separação resistente ao fogo ou incombustível (SILVA; COELHO, 2019). São apresentados os requisitos para transformadores isolados a óleo mineral e a fluidos de alto ponto de combustão, acima de $300{ }^{\circ} \mathrm{C}$, que é o caso do OVI.

Tabela 5: Distâncias mínimas de separação entre transformadores e equipamentos adjacentes

\begin{tabular}{llr}
\hline $\begin{array}{c}\text { Tipo de líquido isolante } \\
\text { do transformador }\end{array}$ & $\begin{array}{c}\text { Volume de líquido } \\
\text { isolante / L }\end{array}$ & $\begin{array}{c}\text { Distância } \\
\text { / m }\end{array}$ \\
\hline $\begin{array}{l}\text { Óleo mineral (ponto de } \\
\text { combustão } \geq 160{ }^{\circ} \mathrm{C} \text { ) }\end{array}$ & Eenor que 2.000 & 1,5 \\
& Entre 2.000 e 20.000 & 7,6 \\
$\begin{array}{l}\text { Fluido de alto ponto de } \\
\text { combustão } \\
\left.\text { (acima de } 300{ }^{\circ} \mathrm{C}\right)\end{array}$ & Menor que 38.000 & 15,2 \\
\hline Fonte: $($ SILVA; COELHO, 2019) & 1,5 \\
\end{tabular}

\section{RESULTADOS E DISCUSSÕES}

\subsection{PROPRIEDADES FÍSICO- QUÍMICAS}

O ponto de combustão é um parâmetro importante do óleo isolante, pois é a temperatura mínima necessária para que gases e vapores combustíveis se desprendam do óleo isolante, e que quando combinado com oxigênio do ar em contato com alguma centelha externa, podem inflamar (CUNHA OTTONI et al., 2003). Por esse motivo, pode-se entender que quanto maior a temperatura mínima estabelecida em norma para o ponto de combustão, melhor é o seu desempenho.

De acordo com a Tabela 1, pode-se observar que o OVI possui ponto de combustão mínimo de $300{ }^{\circ} \mathrm{C}$, enquanto o OMI possui ponto de combustão mínimo de $160{ }^{\circ} \mathrm{C}$. Assim, o OMI traz desvantagens no que se refere a poluição do ar, segurança de operação e confiabilidade operacional caso o transformador atinja o ponto de combustão e comece a queimar, pois emitiria substâncias nocivas na atmosfera, podendo 
causar explosões e consequentemente paradas de operação. O OVI, com a maior temperatura de combustão, apresenta uma maior segurança de operação, visto que a intensidade inicial de um desastre catastrófico, contribuindo para que não haja acidentes provocados por incêndios e emissão de gases de queima no meio ambiente (SILVA; COELHO, 2019).

Já o ponto de fulgor é a característica do óleo isolante que determina a menor temperatura na qual o combustível libera vapor em quantidade suficiente para formar uma mistura inflamável por uma fonte externa de calor (CUNHA OTTONI et al., 2003). Por isso, entende-se que quanto maior o ponto de fulgor, menores serão as chances de o óleo liberar vapor para se tornar uma mistura inflamável. Com o ponto de fulgor elevado, pode-se minimizar ou até reduzir a zero as incidências de explosões ocorridas em transformadores de potência que possuem baixo ponto de fulgor.

Comparando os dois tipos de óleo isolante estudados (OMI e OVI), pode-se observar na Tabela 1 que o OVI possui temperatura mínima do ponto de fulgor, $275{ }^{\circ} \mathrm{C}$, maior que a do OMI, $140{ }^{\circ} \mathrm{C}$. Diante do exposto, o OVI demonstra ser um fluido isolante que apresenta maior segurança em termos de inflamabilidade, uma vez que sua temperatura mínima para liberar vapor e se tornar uma mistura inflamável, é elevada. A Figura 2 apresenta pontos de fulgor e de combustão para o OMI e para três tipos de OVI, Envirotemp 200, Midel 7131 e Envirotemp FR3. Constata-se que o OVI possui valores mais altos, e com isso características de ponto de fulgor e combustão mais atrativas.

As propriedades densidade e viscosidade são parâmetros importantes dos fluidos isolantes aplicados em transformadores de potência, pois indicam a capacidade do fluido isolante em escoar e realizar a refrigeração do transformador. A viscosidade é a propriedade que caracteriza a resistência de um fluido ao escoamento, e a densidade indica a capacidade de o fluido transmitir calor (BRUNETTI, 2008).

Figura 2: Pontos de Fulgor e Combustão dos fluídos dielétricos

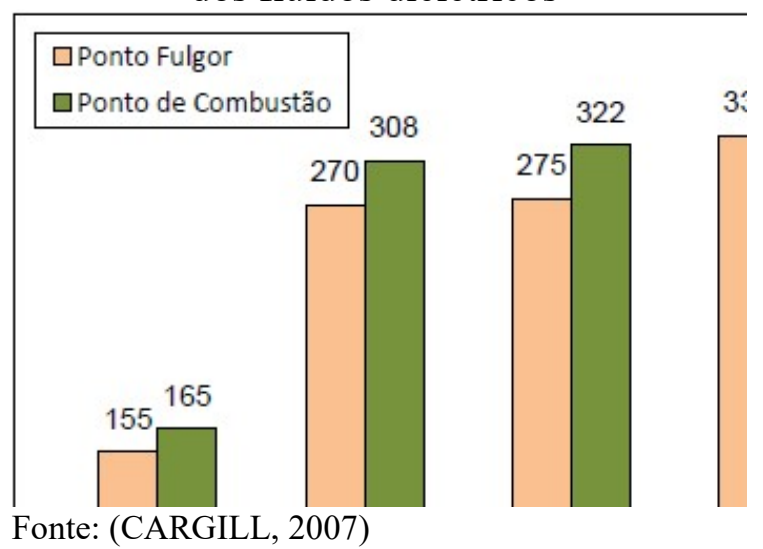

Uma vez que o resfriamento dos transformadores de potência é realizado pelo processo de convecção do fluido isolante, os dois parâmetros (densidade e viscosidade) são muito importantes, do ponto de vista de transferência de calor, para que seja escolhido o sistema de refrigeração mais adequado e o equipamento elétrico não tenha sobrecargas de temperatura. Dessa forma, espera-se que os valores de densidade e viscosidade sejam baixos para melhor circulação e refrigeração do fluido isolante.

Comparando os valores de densidade e viscosidade mostrados na Tabela 1, pode-se observar que o OVI possui valores mais elevados. Por isso, ele se torna um fluido com mais dificuldade de escoamento e refrigeração. No entanto, adotando as medidas corretas no projeto e construção do transformador e no sistema de bombeamento que utilizará o OVI, ele se torna capaz de escoar e refrigerar tal como o OMI (CARGILL, 2007). Com o intuito de se avaliar o impacto dessas medidas no custo dos transformadores, os autores realizaram um levantamento junto a fabricantes brasileiros no segundo semestre de 2019. Verificou-se que para potências entre $30 \mathrm{kVA}$ e $300 \mathrm{kVA}$, classe de tensão $15 \mathrm{kV}$, transformadores típicos em redes de distribuição de energia, os 
transformadores isolados a OVI possuem custo de aquisição da ordem de $6 \%$ acima dos transformadores isolados a OMI. Dessa forma, entende-se que esse é o impacto financeiro no investimento de aquisição do equipamento, que deve ser considerado na análise econômica de seu ciclo de vida.

$\mathrm{Na}$ Figura 3, pode-se observar valores de viscosidade de OVIs para diferentes produtos orgânicos bases de sua fabricação, comparados aos limites estabelecidos na norma NBR 15422. Verifica-se que todos os OVIs ensaiados, bem como o OMI, apresentaram viscosidade dentro dos limites estabelecidos pela norma. $\mathrm{O}$ óleo de babaçu não foi considerado para a temperatura de $20{ }^{\circ} \mathrm{C}$ por não apresentar características fluidodinâmicas adequadas para a utilização como fluido isolante de transformadores nessa temperatura.

Figura 3: Viscosidade dos óleos a (20, 40 e 100) ${ }^{\circ} \mathrm{C}$ comparada aos limites estabelecidos na norma ABNT NBR 15422

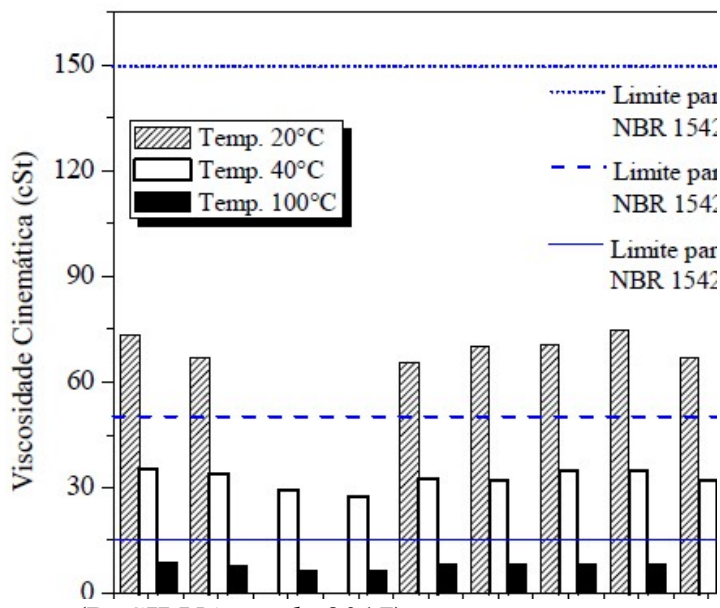

Fonte: (R. SILVA et al., 2017)

O teor de água no óleo isolante é um parâmetro físico-químico muito importante, pois avalia se a umidade é elevada, o que implica significativamente na redução da rigidez dielétrica (CARRIEL, 2012). O teor de água contribui na degradação das propriedades isolantes do óleo, fazendo com que o papel isolante se deteriore mais rapidamente (DA SILVA, 2009).

Analisando a Tabela 1, pode-se observar que o valor máximo permitido de água no OVI é maior do que no OMI (200 $\mathrm{mg} / \mathrm{kg} \quad$ contra $35 \mathrm{mg} / \mathrm{kg}$ ). Essa característica se dá pelo fato de que o óleo vegetal possui uma boa característica higroscópica. Essa característica permite que a água seja retida em sua composição, reduzindo a umidade e concentração de água no papel isolante (VASCONCELLOS, 2016).

A quantidade de água exigida para saturar o OVI à temperatura ambiente é aproximadamente 20 vezes a do OMI. A umidade no óleo mineral isolante age como catalisador na decomposição do papel isolante, que faz com que a vida útil do óleo e consequentemente do transformador seja diminuída (WILHELM; TULIO; UHREN, 2009). Estudos de envelhecimento mostraram que a composição óleo vegetal isolante mais papel isolante tem sua vida estendida, pois a presença de água no óleo vegetal é consumida no processo de hidrólise do triacilglicerol (molécula do OVI), gerando ácidos graxos de cadeia longa (CARGILL, 2007). O processo de hidrólise favorece o deslocamento de mais moléculas de água do papel isolante para o fluido isolante para que se mantenha o equilíbrio químico, ou seja, indiretamente esse deslocamento promove a secagem do papel isolante, o que resulta na extensão da sua vida útil (CARGILL, 2007; VASCONCELLOS et al., 2018). A Figura 4 ilustra a degradação do papel isolante com a utilização de óleo vegetal isolante versus óleo mineral isolante.

Diante disso, pode-se observar que a degradação do papel isolante no transformador ocorre mais lentamente quando isolado a OVI, o que implica em uma maior vida útil do papel isolante, e consequentemente do transformador de potência. Por isso, o OVI possui um teor 
de água com melhores características comparado com o OMI.

Figura 4: Comparação da degradação do papel termo estabilizado imerso em óleo vegetal (à esquerda de cada foto) versus óleo mineral (à direita de cada foto).

Degradação acelerada a $170^{\circ} \mathrm{C}$

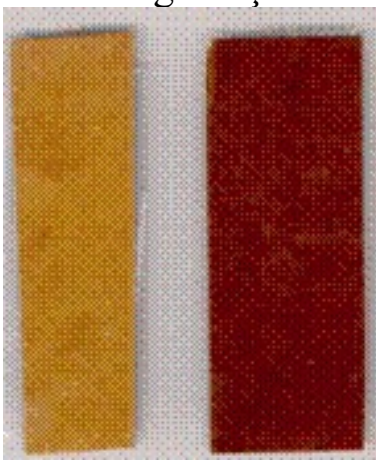

500 horas

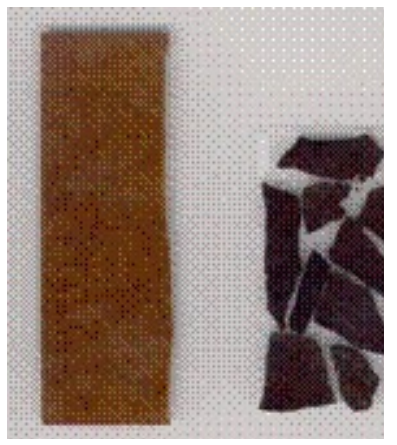

2.000 horas

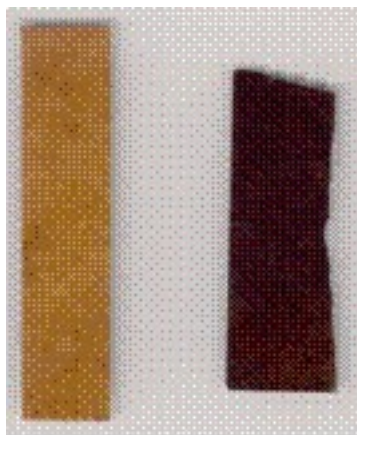

1.000 horas

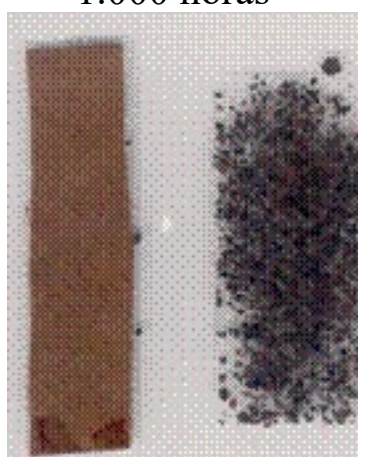

4.000 horas
Fonte: (CARGILL, 2018b)

Seguindo, o índice de neutralização se faz importante de ser analisado, pois avalia a capacidade de isolação e o envelhecimento do óleo isolante. É necessário que o óleo isolante possua um baixo teor de acidez para que se possa minimizar a condução elétrica e corrosão metálica, e assim aumentar a vida útil do sistema isolante e consequentemente do transformador (NOGUEIRA; DOS SANTOS, 2016).

Analisando a Tabela 1, observa-se que o valor do índice de neutralização tolerado para o OVI é maior do que do OMI, o que indica que o OMI apresenta melhores características referente ao índice de neutralização. Essa característica se dá pelo fato de que o OVI tende a formar longas cadeias de ácidos graxos, enquanto o OMI tende a formar cadeias curtas de ácidos orgânicos. Os ácidos graxos de cadeias longas são neutros e não corrosivos em comparação aos ácidos orgânicos de cadeia curta encontrados no óleo mineral (CARGILL, 2007).

Apesar do método de acidez determinar a quantidade de componentes ácidos presentes, ele não indica o tipo ou a reatividade do ácido (CARGILL, 2007). Dessa forma, pode-se concluir que o OVI demanda um valor mais elevado para a neutralização do fluido isolante. Por isso, o OMI possui uma melhor característica relacionada ao índice de neutralização.

Por fim, a rigidez dielétrica define $o$ quanto o óleo pode suportar o campo elétrico ao qual é submetido para não se tornar condutor. Uma vez que o óleo isolante tem o objetivo de isolar as partes ativas do transformador, precisa-se de uma alta rigidez dielétrica para que não prejudique seu funcionamento (NOGUEIRA; DOS SANTOS, 2016). Analisando a Tabela 1, observa-se que o valor da rigidez dielétrica estabelecida pela norma dos dois tipos de óleos isolantes estudados são iguais.

Para análise da rigidez dielétrica, consideremos a diminuição da rigidez dielétrica do OMI e do OVI, que é quando a saturação relativa de água no óleo atinge aproximadamente 50\% (CRUZ, 2015). Para o OMI, a saturação de $50 \%$ à temperatura ambiente corresponde ao intervalo entre (30 a 35) $\mathrm{mg} / \mathrm{kg}$ de água. Já para o OVI, corresponde ao intervalo entre (500 e 600) $\mathrm{mg} / \mathrm{kg}$ de água (WILHELM; TULIO; UHREN, 2009). Ou seja, a quantidade de água para saturar o OVI é aproximadamente 17 vezes maior do que o OMI. Dessa forma, pode-se entender que o OVI possui maior afinidade com a água, que faz com suas características isolantes sejam melhores do que o OMI, implicando em uma melhor rigidez dielétrica. 
3.2 ANÁLISE DE VIDA ÚTIL DOS TRANSFORMADORES ISOLADOS A OVI E OMI

Conforme apresentado na Tabela 2, o transformador isolado a OVI tem vida útil da ordem de $100 \%$ acima do transformador isolado a OMI quando submetidos à mesma temperatura operacional (MENDES, 2008). Seguindo essa análise, pode-se dizer que a taxa de degradação do papel isolante imerso em OMI submetido a uma temperatura máxima (temperatura do ponto mais quente) seria equivalente à taxa de degradação do papel isolante imerso em OVI a uma temperatura superior em $20^{\circ} \mathrm{C}$. Visto isso, é possível verificar que um transformador que utiliza óleo vegetal pode operar "em sobrecarga" e mesmo assim ele terá a mesma vida útil que um transformador que utiliza óleo mineral operando em plena carga (VASCONCELLOS et al., 2018). Assim, pode-se utilizar transformadores de potência na rede de distribuição com uma potência nominal inferior à sua carga, trabalhando em sobrecarga. Nessa condição, ele apresentará as mesmas características do transformador de potência isolado a óleo mineral, com mesma vida útil, porém, com custo reduzido.

Ainda há outra alternativa. Algumas modificações realizadas no transformador de potência que utiliza óleo vegetal, de acordo com a pesquisa realizada por colaboradores da CPFL, tais como modificações nos dutos de resfriamento dos enrolamentos do transformador e um aumento da área de superfície do radiador, fazem com que o transformador aumente a sua capacidade de carga (VASCONCELLOS et al., 2018).

Além da operação em sobrecarga, pode-se utilizar o transformador isolado a óleo vegetal em condições naturais, sem sobrecarga, nas quais haverá aumento de sua vida útil. Essa alternativa é uma ótima opção para distribuidoras de energia, uma vez que o transformador que utiliza OVI não apresentará problemas em um longo período, devido à sua característica de suportar esforços elétrico e mecânicos, e será resistente a sobrecargas. Dessa maneira, pode-se concluir que o transformador que utiliza OVI é uma alternativa a ser considerada, levando em conta que a sobrecarga é a grande causadora de queima de transformadores (BECHARA, 2010). Por isso, o transformador será mais resistente e terá uma expectativa de vida maior.

\subsection{IMPACTOS AMBIENTAIS CAUSADOS PELO DERRAMAMENTO DE ÓLEO ISOLANTE}

Analisando as características referentes aos impactos causados pelos dois tipos de óleo isolante, pode-se verificar que a aplicação do OVI em transformadores de potência se torna mais atrativa, devido à sua biodegradabilidade e não toxidade, o que minimiza ações prejudiciais ao meio ambiente e à saúde humana.

Há de se considerar também uma eventual incidência de multa ambiental por um possível derramamento de OMI no meio ambiente, trazendo impactos negativos e, às vezes, irreparáveis, com contaminação de solos e rios. Além da multa, pode haver necessidade de a organização responsável pela operação do transformador arcar com os danos promovendo ações de recuperação ambiental da área afetada.

Como exemplo, cita-se a incidência de uma multa de R\$ 2.494.000 em novembro de 2012, equivalente a US\$ 1.165.420 à época, imposta à Celesc, devido ao vazamento de 12 mil litros de OMI em uma subestação do estado de Santa Catarina, Brasil (G1 SC, 2018). Nota-se valor específico de R\$ 208 por litro de OMI derramado, ou US\$ 97 / L. Em levantamento feito pelos autores em uma distribuidora de energia elétrica do 
Brasil, para fins de ilustração, os resultados daquela amostragem apontaram para a probabilidade de $0,0048 \%$ de ocorrência de um derramamento por ano de óleo isolante para cada transformador daquela rede de distribuição. Por meio de técnicas de gerenciamento de risco, esse conjunto de informações estima o impacto econômico de multas ambientas por derramamento de óleo isolante (DA SILVA; MATA-LIMA, 2019).

\subsection{SEGURANÇA OPERACIONAL DOS TRANSFORMADORES ISOLADOS A OVI E OMI}

Analisando a Tabela 4, observa-se que $o$ fluido a base de oleaginosas apresenta taxa de perigo ao fogo em menor escala, cerca de $4 \%$ a $5 \%$ contra $10 \%$ a $20 \%$ para o OMI. Por isso, torna-se um fluido com menos riscos de explosões e incêndios. Fluidos isolantes que possuem ponto de combustão acima de $300{ }^{\circ} \mathrm{C}$, considerados fluidos de classificação $\mathrm{K}$, reduzem a intensidade inicial de um desastre catastrófico em transformadores e impedem incêndios (SILVA; COELHO, 2019). Além do alto ponto de combustão, o OVI também apresenta baixa concentração de gases combustíveis, o que diminui o risco de explosões (CARGILL, 2007). Dessa forma, a utilização do OVI em transformadores de potência torna-se uma alternativa mais resistente e segura, comparada ao OMI.

Analisando os dados da Nesse contexto de perigo ao fogo, a Erro! Autoreferência de indicador não válida. apresenta as distâncias mínimas exigidas para separação entre transformadores de potência e outros equipamentos quando não há parede de separação resistente ao fogo ou incombustível (SILVA; COELHO, 2019). São apresentados os requisitos para transformadores isolados a óleo mineral e a fluidos de alto ponto de combustão, acima de $300{ }^{\circ} \mathrm{C}$, que é o caso do OVI.
Tabela 5: Distâncias mínimas de separação entre transformadores e equipamentos adjacentes

\begin{tabular}{llr}
\hline $\begin{array}{c}\text { Tipo de líquido isolante } \\
\text { do transformador }\end{array}$ & $\begin{array}{c}\text { Volume de líquido } \\
\text { isolante / L }\end{array}$ & $\begin{array}{c}\text { Distância } \\
\text { / m }\end{array}$ \\
\hline $\begin{array}{l}\text { Óleo mineral (ponto de } \\
\text { combustão } \geq 160^{\circ} \mathrm{C} \text { ) }\end{array}$ & Entre 2.000 e 20.000 & 1,5 \\
& Maior que 20.000 & 7,6 \\
$\begin{array}{l}\text { Fluido de alto ponto de } \\
\text { combustão }\end{array}$ & Menor que 38.000 & 15,2 \\
$\left(\right.$ acima de $\left.300^{\circ} \mathrm{C}\right)$ & Maior que 38.000 & 1,5 \\
\hline
\end{tabular}

Fonte: (SILVA; COELHO, 2019)

\section{RESULTADOS E DISCUSSÕES}

\subsection{PROPRIEDADES FÍSICO- QUÍMICAS}

O ponto de combustão é um parâmetro importante do óleo isolante, pois é a temperatura mínima necessária para que gases e vapores combustíveis se desprendam do óleo isolante, e que quando combinado com oxigênio do ar em contato com alguma centelha externa, podem inflamar (CUNHA OTTONI et al., 2003). Por esse motivo, pode-se entender que quanto maior a temperatura mínima estabelecida em norma para o ponto de combustão, melhor é o seu desempenho.

, constata-se que o OVI pode proporcionar melhor aproveitamento da área onde será instalado, permitindo a redução das distâncias entre equipamentos e edificações, e em alguns casos eliminando o uso de paredes corta-fogo.

\section{CONCLUSÕES}

As análises realizadas mostraram que as características físico-químicas do OVI na maioria dos parâmetros são melhores que as do OMI. Mesmo quando o OMI se apresentou mais atrativo, o OVI ainda possuía parâmetros dentro dos limites estabelecidos em normas técnicas.

$\mathrm{Na}$ análise da vida útil, o OVI revelou uma expectativa de vida mais elevada, pois o OVI possui maior afinidade com a água, fazendo com que seja reduzida a degradação do papel isolante. Empresas 
do setor elétrico já estão começando o processo de substituição desses equipamentos para contribuírem com o meio ambiente e para que tenham um equipamento com maior segurança e com elevação da expectativa de vida útil.

$\mathrm{Na}$ análise dos impactos ambientais, observou-se que o OVI apresenta menos riscos ao meio ambiente caso ocorra vazamento, por ser um fluido a base de oleaginosas e biodegradável. A ocorrência de vazamentos no ambiente poderá afetar toda uma comunidade e gerar custos para a empresa responsável. Por isso, o óleo vegetal se torna um candidato atrativo para substituição em redes de distribuição.

$\mathrm{Na}$ análise das condições de operação, do ponto de vista de segurança, o transformador que utiliza o OVI apresentou-se mais seguro, devido ao seu alto ponto de combustão e fulgor que o torna um fluido resistente ao fogo.

Como o transformador é um equipamento de vida útil relativamente elevada, da ordem de dezenas de anos, não é esperada uma substituição imediata e em larga escala dos transformadores em operação isolados a OMI por novos isolados a OVI. Entretanto, em consonâncias às vantagens técnicooperacionais evidenciadas e ao baixo investimento marginal, verifica-se a tendência de adoção do transformador isolado a OVI em novos projetos e em substituição a transformadores retirados de operação em diversas distribuidoras de energia do Brasil.

\section{AGRADECIMENTOS}

À Cargill, Inc. por disponibilizar materiais e informações técnicas.

À Itaipu Transformadores, por fornecer dados técnicos e econômicos de transformadores.

À EDP Energias, por ceder informações relativas a transformadores de redes de distribuição.

\section{REFERÊNCIAS}

BECHARA, R. Análise de falhas de transformadores de potência. Escola Politécnica da Universidade de São Paulo, 2010.

BRUNETTI, F. Mecânica dos fluidos. $2^{\mathrm{a}}$ ed. São Paulo: Pearson, 2008.

CARGILL. Fluido Envirotemp FR3 Guia de Armazenamento, Instalação, Comissionamento e Manutenção de Transformadores com Fluido FR3, 2007.

CARGILL. Subestação de energia da Eletropaulo utiliza óleo vegetal em transformadores. Disponível em: https://www.cargill.com.br/cs/Satellite?c= CGL_PressRelease_C\&childpagename $=\mathrm{C}$ SF_BR\%2FCGL_PressRelease_C\%2FCC OM\%2FNav1Layout\&cid=143211681867 4\&pagename $=$ CCOM_Wrapper. Acesso em: 31 maio. 2018a.

\section{CARGILL. Fluido Envirotemp FR3 formulado para um melhor desempenho, $2018 \mathrm{~b}$.}

\section{CARGILL. Empresa Luz e Força Santa} Maria S/A adquire Transformadores de distribuição com óleo vegetal. Disponível em: https://www.cargill.com.br/pt_BR/ 2020/santamaria. Acesso em: 31 maio. 2020 .

CARRIEL, L. P. Carregamento e Envelhecimento de Transformadores Elétricos de Potência e Aspectos Prioritários Para a Manutenção Baseada na Condição. Universidade Estadual de Campinas - UNICAMP, 2012.

\section{CRUZ, D. A. Estudo das curvas de} permeabilidade relativa água-óleo considerando o efeito de forças capilares na produção adicional de óleo. Rio de Janeiro, Brasil: Universidade Federal do Rio de Janeiro, 2015. 
CUNHA OTTONI, D. et al. Fogo e Incêndio. Universidade Federal do Rio Grande do Norte, p. 1-8, 2003.

DA SILVA, C. R. Propriedades físicoquímicas e dielétricas de óleos vegetais para uso como isolante em transformadores. Campina Grande, Brasil: Universidade Federal de Campina Grande, 2009.

DA SILVA, M. C. G.; MATA-LIMA, H. Oil spill risk management in the coastal zone: the case of Port of Santos. Finisterra

- Revista Portuguesa de Geografia, v. 111, p. 61-80, 2019.

DATALINK. Funções do óleo isolante para transformador. Disponível em: http://datalink.srv.br/artigos-tecnicos/ funcoes-do-oleo-isolante-paratransformador/. Acesso em: 24 mar. 2020.

FEIL, D. L. P. et al. Development of an efficient distribution transformer using amorphous core and vegetable insulating oil. Electric Power Systems Research, v. 144, p. 268-279, 2017.

FRIEDENBERG, L. E.; SANTANA, R. M. C. Properties of insulating oils of transformers and the protection of the environment. IX International Symposium on Environmental Quality. Anais...Porto Alegre - RS - Brazil: ABES-RS, 2014. Disponível em: http://www.abesrs.org.br/qualidade2014/trabalhos/id868.pd f.

G1 SC. Instituto do Meio Ambiente multa Celesc em R\$ 2,5 milhões por vazamento de óleo na Tapera em 2012. Disponível em: https://g1.globo.com/ sc/santa-catarina/noticia/2018/07/19/ instituto-do-meio-ambiente-multa-celescem-r-25-milhoes-por-vazamento-de-oleona-tapera-em-2012.ghtml. Acesso em: 29 mar. 2020.

GARCIA, F. M. C. Os impactos econômicos e os danos socioambientais do vazamento de ascarel na capital de Santa Catarina - Brasil. In: HAONAT, A. I.; REZENDE, E. N.; SALEME, E. R. (Eds.). Direito Ambiental V: XXIII Congresso Nacional do CONPEDI. Florianópolis: COPENDI, 2014. p. 336-350.

GOUVEIA, D. A. G. Determinação de gases combustíveis em óleo isolante para transformadores, por meio de aquecimento prévio. São Carlos, Brasil: USP, 5 maio 2008.

GUIMARÃES, D. H. P. et al. Physicochemical analysis of biodiesel obtained from blends of virgin castor oil and waste frying oil. Revista de Ciencia y

Tecnología, n. 32, p. 11-15, 4 nov. 2019.

MARTINS, C. Estudo para Utilização de Óleo Vegetal em Transformadores Subterrâneos Redes Subterrâneas. XIII Expo \& Fórum - Redes Substerrâneas de Energia Elétrica. Anais...São Paulo: 2017.

MENDES, J. C. BIOTEMP - Óleo

Vegetal da ABB - Aplicação em Transformadores de Potência em Alta Tensão Rio de Janeiro, CEPEL, 2008.

MOURA, N. K. DE; ANDRADE, Y. Method for the Evaluation and Classification of Power Transformer Insulating Oil Based on Physicochemical Analyses. IEEE Electrical Insulation Magazine, v. 33, n. 1, p. 39-49, 2017.

NOGUEIRA, D. DA S.; ALVES, D. P. Transformadores de potência - Teoria e aplicação - Tópicos essenciais. Rio de Janeiro, Brasil: UFRJ, 2009.

NOGUEIRA, I.; DOS SANTOS, M. M. M. Descritores físico-químicos para ação preditiva de dielétricos líquidos em transformadores de energia: estudo de caso da CPFL Paulista. Itajubá, Brasil: Universidade Federal de Itajubá, 2016.

OLIVEIRA, M. E. DE. Avaliação de Metodologias de Cálculo de Perdas 
Técnicas em Sistemas de Distribuição de Energia Elétrica. Ilha Solteira - SP, Brasil: UNESP, 2009.

R. SILVA, C. et al. Caracterização físicoquímica e dielétrica de óleos biodegradáveis para transformadores elétricos. Journal of Conflict Resolution, n. 16, p. 229-234, 2017.

SEG MAQS. Transformador de energia elétrica. Disponível em: http://www. segurancaemmaqs.com.br/transformador/. Acesso em: 28 mar. 2020.

SILVA, R. I. DA; COELHO, A. A nova instrução técnica n ${ }^{\circ} 37$ / 2018 subestação elétrica, do Corpo de Bombeiros do estado de São Paulo e o reconhecimento dos benefícios do uso de transformadores e reatores imersos em fluido isolante de alto ponto de combustão (classe K). XVIII ERIAC. Anais... Foz do Iguaçu: Cigre CENN, 2019.

SIMONE, G. O uso de óleo vegetal em transformadores de distribuição de energia elétrica. Araranguá-SC, Brasil: UFSC, 2017.

STOCCO, M. B. C. Avaliação do potencial de aplicação de óleos vegetais como fluidos isolantes em transformadores de distribuição da rede elétrica. Curitiba - PR, Brasil:

Universidade Federal do Paraná, 2010.

UNDERWRITERS LABORATORIES.

UL 340 - Standard for Tests for Comparative Flammability of Liquids UL LLC, 2017. Disponível em: https:// standardscatalog.ul.com/standards/en/stand ard_340.

VASCONCELLOS, V. Compactação e elevação da vida útil de transformadores de distribuição empregando óleo vegetal isolante. São Paulo: Universidade de São Paulo, 5 jul. 2016.
Loadability of Transformers Using Natural Ester and Cellulosic Materials as High Temperature Insulation Systems. IEEE Electrical Insulation Magazine, v. 34, p. 8-17, 2018.

WILHELM, H. M.; TULIO, L.; UHREN, W. Produção e uso de óleos vegetais isolantes no setor elétrico. Engenharia, v. 592, p. 120-124, 2009.

ZIRBES, R.; ROLIM, J. G.; ZÜRN, H. H. Metodologias para avaliação e diagnóstico do estado de isolamentos de papel impregnado com óleo mineral. Sba: Controle \& Automação Sociedade Brasileira de Automatica, v. 16, n. 3, p. 318-331, set. 2005.

VASCONCELLOS, V. et al. Increased 